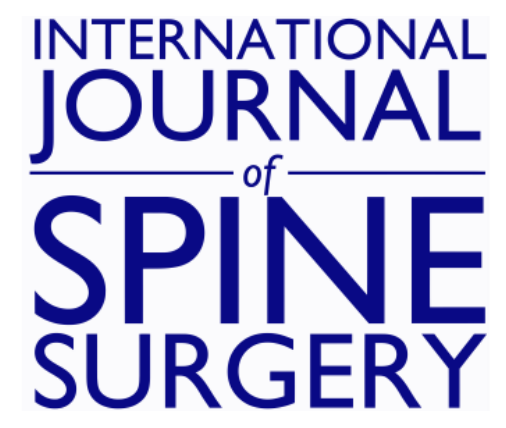

\title{
Minimally Invasive Excision of Lumbar Tophaceous Gout: Case Report
}

Pierluigi Vergara and Dominic G O'Donovan

Int J Spine Surg 2017, 11 (5)

doi: https://doi.org/10.14444/4037

http://ijssurgery.com/content/11/5/37

This information is current as of April 26, 2023.

Email Alerts Receive free email-alerts when new articles cite this article. Sign up at:

http://ijssurgery.com/alerts 


\section{Minimally Invasive Excision of Lumbar Tophaceous Gout: Case Report}

Pierluigi Vergara MD FRCS, ${ }^{1}$ Dominic G O'Donovan MBChB FRCPath²

${ }^{1}$ Department of Neurosurgery, Addenbrooke's Hospital, Cambridge University Hospital, Cambridge, UK, 2Department of Histopathology, Addenbrooke's Hospital, Cambridge University Hospital, Cambridge, UK

\section{Abstract}

\section{Background}

Symptomatic spinal gout is relatively rare. Open laminectomy, with or without fusion, has been so far the standard treatment for symptomatic spinal gout. We describe here the first case of spinal tophaceus gout treated with minimally invasive surgery.

\section{Methods}

A 60-year-old patient, morbidly obese, with no previous history of gout, presented with neurogenic claudication due to severe lumbar canal stenosis at L3/4. Surgery was performed through a minimally invasive approach, using tubular retractors. During surgery, an extradural mass with a thin capsule and containing white "chalky" partially calcified material, slightly adherent to and compressing the theca, was removed.

Results

There were no intra- or perioperative complications. Surgery successfully improved the functional status, with a significant increase in walking distance and no residual leg pain or neurogenic claudication. Histopathology confirmed the diagnosis of spinal tophaceous gout.

\section{Conclusions/Level of evidence}

Although spinal gout is usually responsive to medical treatment, surgery is often the first line treatment, particularly in patients with neurological deficits. Would surgery be indicated, we believe that minimally invasive surgery can be effective in treating symptomatic spinal tophaceous gout. Level of Evidence: Class IV.

MINIMALLY INVASIVE SURGERY

KEYWORDS: TOPHACEOUS GOUT, TOPHI, MINIMALLY INVASIVE, SPINE, LUMBAR

VOLUME 11 ISSUE 5 DOI: 10.14444/4037

PAGES $305-309$

\section{Introduction}

The incidence of gout is estimated to be $0.2-0.4 \%$ worldwide. ${ }^{1}$ Recent reports have shown an increase in the incidence; in fact almost $4 \%$ of the US population is affected by gout. ${ }^{2}$

Gout most commonly affects joints of hands, feet, knees, ankles and wrists. Although less frequently, gout could also involve the spine, with unknown frequency. Between $14 \%$ and $22 \%$ of patients with gout might have radiographic abnormalities of the spine, ${ }^{3,4}$ although these are often non-specific.

The presence of tophi indicates that patient has had chronic gout for 5-10 years.,
Gout could involve all the segments of the spine but it appears to be more common in the lumbar spine (44-54\%). ${ }^{7,8}$ Deposits of tophaceous gout could be found in any part of the vertebra, including facet joint, ${ }^{9}$ vertebral body, ${ }^{10}$ pedicle,${ }^{11}$ lamina, ${ }^{12}$ ligamentum flavum, ${ }^{13}$ and disc. ${ }^{14,15}$

Symptomatic spinal gout can present with features of back pain, spinal stenosis, myelopathy, radiculopathy and cauda equina syndrome.

One hundred and thirty three cases of spinal gout have been reported in the literature so far. ${ }^{8}$ Surgery, in the form of open laminectomy with or without fusion, appears to be still the first line treatment, with adjuvant medical treatment, particularly in patients 
presenting with neurological deficits.

Here we report the first case of symptomatic spinal tophaceous gout operated via a minimally invasive approach.

\section{Materials and Methods}

History and Presentation

A 60 years old lady, morbidly obese (BMI 51), presented with four months history of debilitating lower back and right leg pain, associated with weakness and paraesthesiae. The patient was pretty much wheelchair bound, with walking distance limited to few steps only. No relevant medical history recorded. Neurological examination showed mild bilateral distal leg weakness (4/5), slightly more marked on the right side, reduced sensation to light touch on L4 and L5 distribution on the right and absent reflexes in both legs.

\section{Imaging Studies}

Due to claustrophobia and very high BMI, the patient was unable to undergo Magnetic Resonance of the spine. Dynamic lumbar Xrays showed diffuse degenerative changes with no evident instability at L3/ 4. A CT-myelogram showed severe lumbar stenosis at L3/4, with complete obliteration of the canal, and moderate stenosis at $\mathrm{L} 2 / 3$.

Due to the poor quality images obtained, the lumbar stenosis was thought to be mostly degenerative in nature, with no suspicion of intraspinal gout (Figure 1A and Figure 1B).

\section{Operation}

The patient was positioned prone, on an adapted Wilson frame for high BMI. We performed the operation using our standard minimally invasive technique for lumbar decompression via tubular retractors. Sequential dilators were inserted through a $2 \mathrm{~cm}$ skin incision, up to $18 \mathrm{~mm}$ of maximum diameter, and docked at the junction between the right lamina and the spinal process. A right L3 hemilaminotomy was performed with high-speed drill. The retractor was then angled more medially, toward the midline, and the operating table away from the surgeon, to allow access to the contralateral lateral recess. After drilling of the base of the spinal process and the ventral aspect of the left lamina, the ligamentum flavum was excised. An extradural mass with a thin capsule and containing white "chalky" partially calcified material, slightly adherent to and compressing the theca, was unexpectedly seen. After removal of the lesion, a full decompression of the theca, from edge to edge, was achieved.

Surgical time was 2 hours and estimated blood loss less than $50 \mathrm{ml}$.

\section{Results}

There were no intra- or perioperative complications. The patient reported immediate improvements of the symptomatology with no leg pain and less paraesthesiae. She was discharged home 24 hours postoperatively.

The histopatology was later to show compatible with Chronic Tophaceous Gout (Figure 2).

She was therefore referred to Rheumatology and started on Allopurinol.

Six months postoperatively, at her last follow-up, she reported excellent improvements with complete resolution of the preoperative leg pain and significant improvements of the paraesthesiae. Walking distance, still limited by high BMI related issues, increased to more than 100 meters.

\section{Discussion}

Gout was first described within the spine by Kersley et al in $1950 .{ }^{16}$ It is characterized by the deposition of monosodium urate crystals and by acute and chronic inflammation in response to crystals deposited.

In a recent comprehensive review, back pain was the most common symptom (68.5\%), while neurological impairment was present in $65.4 \%$ cases, with the two not being mutually exclusive. ${ }^{8}$

Blood tests usually show increased serum acid uric $(>7 \mathrm{mg} / \mathrm{dL})$ and raised inflammatory markers (ESR, CRP, WBC). 
MRI findings are often non-specific, with only $21 \%$ of cases unequivocally interpreted as spinal gout, as shown by a recent review. ${ }^{8}$ In fact, gout tophi on MRi scan can appear as homogeneous areas of intermediate- to hypointensity signal on $\mathrm{T} 1$ and hyper- to hypointensity in T2. After gadolinium, the tophi show homogeneous or heterogeneous marginal enhancement, as result of well-vascularized chronic, inflammatory fibrous tissue, engendered by urate crystal deposition. ${ }^{7,17}$ CT, PET-CT and DECT scans could help with the diagnosis but they are not routinely performed in addition to MRi scans.
Due to the inconsistency between laboratory tests, radiological and clinical findings, the diagnosis is usually made during surgery. Intraoperatively, gouty tophi appear typically as chalky white nodules or masses, usually easily removed with suction, although the capsule of the mass can be sometimes adherent to the dura.

Under microscopy, the urate depositions are surrounded by multinucleated histiocytes, which are giant cells with foreign bodies associated with lymphoplasmocytic cells and fibroblasts.

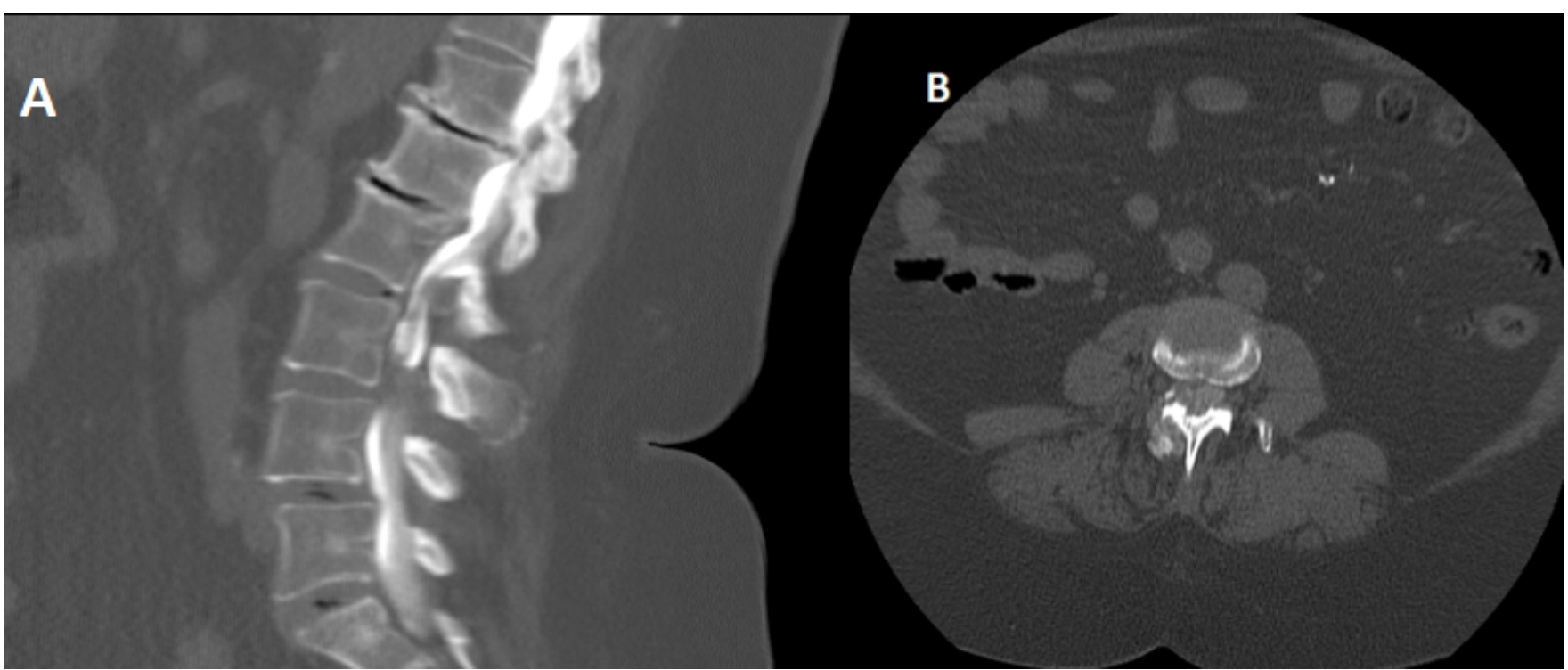

Fig. 1. Sagittal (A) and axial (B) CT-myelogram showing severe lumabr canal stenosis at L3/4, with complete obliteration of the canal, and moderate stenosis at $\mathrm{L} 2 / 3$.

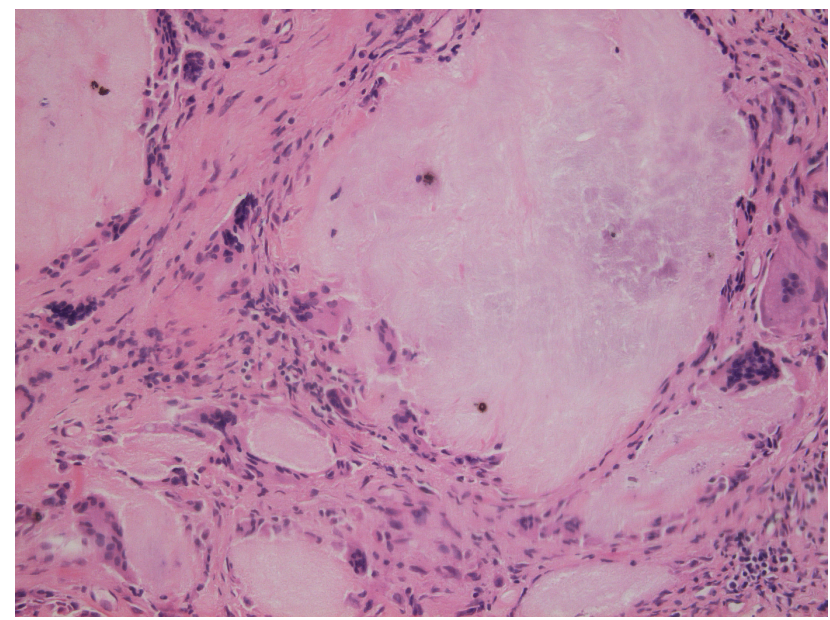

Fig. 2. Histopathology section (x20) showing fibrous tissue with pools of amorphous debris with a foreign body giant cell reaction. Due to processing the crystals are not visible and polarisation is negative. Nevertheless, this is typical of urate gout. 
Although a recent report suggests that conservative treatments can be as effective as surgical treatments, the first line treatment is usually surgery, reaching $61 \%$ of the cases report of spinal gout described in the literature. ${ }^{8}$ Surgery is usually most common in cases with neurology or where the differential diagnosis is suspicious of unfavourable pathologies such as infections or tumors.

Surgery usually consists of an open laminectomy or decompression, sometimes associated with fusion. In our case we have adopted a minimally invasive approach, similar to the one commonly used by the author for addressing degenerative lumbar canal stenosis. This has the advantage of a smaller incision, less soft tissue disruption, preservation of midline and contralateral structures. It has shown to be effective in addressing the pathology, as well as being extremely well tolerated by the patient (minimal blood loss, minimal postoperative pain, no intraoperative complication, etc). In our specific case, with very high $\mathrm{BMI}$ and high risk of perioperative morbidity, performing surgery via a minimally invasive approach with a very small incision $(2 \mathrm{~cm})$ has also allowed to reduce significantly the risk of wound related issues, which are very common in this category of patients. However, while there was no complication like dural tear in this one particular case, the usual care should be taken when performing these types of procedures as the rates of dural tear and nerve injury are likely to be just as high as for minimally invasive lumbar decompression.

We therefore believe that minimally invasive decompression and excision of spinal tophi can be a valid and safe alternative to open approaches, would surgery be indicated. In fact, we believe that large laminectomies or more invasive spinal fusions can be avoided, especially considering the benign course of the pathology, which can be further treated with medications.

Due to the low incidence of symptomatic spinal gout (133 cases in the literature), we assume that large randomised studies would be extremely hard to be performed but, based on our experience, we advocate that minimally invasive approaches could be used when treating symptomatic spinal gout.

\section{Conclusion}

Symptomatic tophaceous spinal gout is a relatively rare condition. Although responsive to medical treatment, surgery in the form of laminectomy and excision of the tophi, is often the first line treatment, particularly in patients with neurological deficits or were the differential diagnosis include malignant or infective processes. Would surgery be indicated, we believe that minimally invasive surgery can be effective in treating symptomatic spinal tophaceous gout.

The patient consented to submission of this case report to the journal.

\section{References}

1. Hall AP, Barry PE, Dawber TR, McNamara PM. Epidemiology of gout and hyperuricemia. A longterm population study. Am J Med. 1967;42(1):27-37. 2. Zhu Y, Pandya BJ, Choi HK. Prevalence of gout and hyperuricemia in the US general population: the National Health and Nutrition Examination Survey 2007-2008. Arthritis Rheum. 2011;63(10):3136-3141. doi:10.1002/art.30520

3. Jajic I. Gout in the spine and sacro-iliac joints: radiological manifestations. Skeletal Radiol.

1982;8(3):209-212.

4. Konatalapalli RM, Demarco PJ, Jelinek JS, et al. Gout in the axial skeleton. J Rheumatol. 2009;36(3):609-613. doi:10.3899/jrheum.080374

5. Yu JS, Chung C, Recht M, Dailiana T, Jurdi R. MR imaging of tophaceous gout. AJR Am J Roentgenol. 1997;168(2):523-527. doi:10.2214/ ajr.168.2.9016240

6. Kotake S, Nanke Y. Spinal tophaceous gout. Intern Med. 2012;51(3):237-238.

7. King JC, Nicholas C. Gouty arthropathy of the lumbar spine: a case report and review of the literature. Spine (Phila Pa 1976). 1997;22(19):2309-2312. 8. Toprover M, Krasnokutsky S, Pillinger MH. Gout in the Spine: Imaging, Diagnosis, and Outcomes. Curr Rheumatol Rep. 2015;17(12):70. doi:10.1007/s11926-015-0547-7

9. Hasturk AE, Basmaci M, Canbay S, Vural C, Erten F. Spinal gout tophus: a very rare cause of radiculopathy. Eur Spine J. 2012;21 Suppl 
4:S400-403. doi:10.1007/s00586-011-1847-x

10. Dharmadhikari R, Dildey P, Hide IG. A rare cause of spinal cord compression: imaging appearances of gout of the cervical spine. Skeletal Radiol. 2006;35(12):942-945. doi:10.1007/

s00256-006-0088-2

11. Chan AT, Leung JL, Sy AN, et al. Thoracic spinal gout mimicking metastasis. Hong Kong Med J. 2009;15(2):143-145.

12. Cabot J, Mosel L, Kong A, Hayward M. Tophaceous gout in the cervical spine. Skeletal Radiol.

2005;34(12):803-806. doi:10.1007/

s00256-005-0920-0

13. Zheng ZF, Shi HL, Xing Y, Li D, Jia JY, Lin S. Thoracic cord compression due to ligamentum flavum gouty tophus: a case report and literature review. Spinal Cord. 2015;53(12):881-886. doi:10.1038/ sc. 2015.93

14. Sanmillan Blasco JL, Vidal Sarro N, Marnov A, Acebes Martin JJ. Cervical cord compression due to intradiscal gouty tophus: brief report. Spine (Phila Pa 1976). 2012;37(24):E1534-1536. doi:10.1097/ BRS.0b013e31826f2886

15. Yen HL, Cheng CH, Lin JW. Cervical myelopathy due to gouty tophi in the intervertebral disc space. Acta Neurochir (Wien). 2002;144(2):205-207. doi:10.1007/s007010200026
16. Kersley GD, Mandel L, Jeffrey MR. Gout; an unusual case with softening and subluxation of the first cervical vertebra and splenomegaly. Ann Rheum Dis. 1950;9(4):282-304.

17. Hsu CY, Shih TT, Huang KM, Chen PQ, Sheu JJ, Li YW. Tophaceous gout of the spine: MR imaging features. Clin Radiol. 2002;57(10):919-925.

\section{Disclosures \& COI}

The authors report no conflict of interest concerning the materials or methods used in this study or the findings specified in this paper.

\section{Corresponding Author}

Pierluigi Vergara, Box 166 - Department of Neurosurgery, Addenbrooke's Hospital, Cambridge University Hospitals, Hills Road, CB20QQ. spinalneuro@gmail.com.

Published 5 December 2017.

This manuscript is generously published free of charge by ISASS, the International Society for the Advancement of Spine Surgery. Copyright @ 2017 ISASS. To see more or order reprints or permissions, see http://ijssurgery.com. 